\title{
Basic School Skills Inventory-3: Validity and Reliability Study
}

\author{
F. Ülkü Yıldız ${ }^{1}$, Aysel Çağdaş ${ }^{1}$, Gökhan Kayıl1 ${ }^{1}$ \\ ${ }^{1}$ Faculty of Health Sciences, Department of Child Development, Selcuk University, Konya, Turkey \\ Correspondence: Gökhan Kayıll, Faculty of Health Sciences, Department of Child Development, Selcuk University, \\ Kampus, 42250, Konya, Turkey.
}

Received: April 26, 2017

doi:10.11114/jets.v5i7.2485
Accepted: June 8, $2017 \quad$ Online Published: June 13, 2017

URL: https://doi.org/10.11114/jets.v5i7.2485

\begin{abstract}
The purpose of this study is to perform the validity-reliability analysis of the three subtests of Basic School Skills Inventory 3 - Mathematics, Classroom Behavior and Daily Life skills - and do its adaptation for four to six year-old Turkish children. The sample of the study included 595 four to six year-old Turkish children attending public and private schools. The schools were selected from among the central towns of the province Konya based on random sampling method considering the social-economic conditions. For the reliability of the subtests of the Basic School Skills Inventory - that's Mathematics, Classroom Behavior and Daily Life and Skills - analyses were made to determine the internal consistency (Cronbach's Alpha), split-test reliability and test-retest reliability coefficient. The validity of the inventory was measured using construct, content and concurrent validity. The results showed that the Basic School Skills Inventory - Mathematics, Daily Life and Classroom Behavior Skills - was a reliable and valid instrument for Turkish children aged four to six years.
\end{abstract}

Keywords: basic school skills; mathematic skills; daily life skills; classroom behavior; preschool education

\section{Introduction}

Early childhood is a time to honor curiosity and encourage a love of learning and school. Learning is an autonomous and a lifelong process which includes not only a new skill or specialization in a certain academic area but also emotional development, social interaction and even personality development (Atkinson, Atkinson, Smith, Bem, \& Hoeksema, 1999; Montessori, 2016). The learning should be such as to contribute to the development of a child. Previously acquired skills pave the way for the new skills. According to the epigenetic principle, a growing organism has a basic plan. The parts of the organism grows in a certain time and order based on this basic plan. Every stage acts as a step for the next one and is formed depending on the effect of the previous ones. The previous stage involves in itself the core features supposed to grow during next stages (Öztürk, 1994). If the development of a child is seen as knitting, then a child without sensory development should be regarded as a knitting work with a loop not made yet (Montessori, 1978, Montessori, 2015). Young children sensitive to learning and development are supposed to have acquired certain skills, habits, behaviors and concepts in this period. At ages 3 to 6 years, however, ego functions such as memory, thinking and judgment are a bit weak to develop. Ego's capacity to function is yet to be developed. Children try to overcome this incapacity of ego turning to their parents or an adult (Ekşi, 1999).

Inadequacy in basic skills could result from indifference, ignorance and some shortcomings in practice. Children's socio-emotional skills and behaviors affect individual learning and classroom dynamics. Weakness of Interpersonal skills lead to child-teacher conflict, and the factors of stress and social exclusion are likely to decrease children's involvement (Newcomb, Bukowski \& Patte, 1993).

Parents as well as teachers have responsibility for facilitating children's development of cognitive skills (Gander \& Gardiner, 2007). Though basic school skills are commonly perceived as reading, writing and simple mathematical concepts, skills such as moving back and forth, climbing up the stairs on their own and getting dressed and undressed should be acquired in advance and children, for example, need to interact with books at early ages in order to read and learn to walk before they can ride a tricycle. For a healthy life and independence, they need to learn daily skills such as brushing teeth, using a spoon or fork, drinking from a glass, washing and drying hands, combing hair and sleeping well (Trawick-Smith, 2013).

Mathematical skills cover a broader network of skills including language, physical and social skills that children 
develop initially. Each of these skill areas depends on and affects the others. Children might be strong in some mathematical skills while weak in others. Mathematical skills, in fact, depend on each other; symbols, conceptual equivalences of symbols and the content of symbols... counting, understanding numbers, understanding geometric shapes, identifying and adding (Yıldız \& Kayll, 2015). A study by Duncan, Dowsett, Claessens, Magnuson, Huston, Klebanov and Sexton (2007) found that early mathematical skills, followed by reading and attention, play a significant role in children's increased academic success whereas economic condition and gender have no effect on it.

Some children experience slight delays in learning. It is easy to follow children's height and weight. Nevertheless, how can you measure your child's development in other areas? For instance, can you understand that $\mathrm{s} / \mathrm{he}$ has learnt and is practicing appropriate daily life skills? What about classroom behaviors? Or how good is s/he at mathematical skills? Parents need to spend time with their children so that they can realize this inadequacy. Even when they are doubtful about a hardship in their learning, parents tend to wait for a long time without seeking help in order to avoid stigmatizing their child. Here, early intervention could make a significant contribution. When the basic skills are acquired at early ages, then it becomes easier to pick up higher skills. Development of skills at early ages has to do with more effective, long-term arrangements. When high-quality programs are administered to the children at risk, not only do they easily learn cognitive and academic skills that increase their school success but noticeable improvements are made in problem behaviors, as well (Karoly, Kilburn \& Cannon, 2005).

The Basic School Skills Inventory-3, which is believed to measure these skills, behaviors and concepts at ages four to six years, has been developed since 1976 and the latest modifications and statistical studies were made in 1996 (Hammill, Leigh, Pearson \& Maddox, 1998). Turkish adaptation is needed as it is a comprehensive basic school skills inventory. These kinds of measuring tools are essential to develop a road map to support children's development as they help discover the strengths and weaknesses in early childhood.

\section{Method}

\subsection{Design of the Study}

The purpose of this study is to adapt Basic School Skills Inventory-3 to Turkish children and perform the reliability and validity analysis of the test. Thus, the general survey model was used in the study. General survey models are a type of research that presents the current situation as it exists.

\subsection{Sample of the Study}

Sample of the study included 99 (16.7\%) four-year old, $244(41.0 \%)$ five-year old and $252(42.3 \%)$ six-year old children (595 children in total) from public and private nursery schools in central districts of Konya. Children were selected through simple random sampling method considering different socio-economic conditions based on teacher views. Of four year old children, $48 \%$ were girls and 52\% were boys; five-year old children included 54\% girls and $46 \%$ boys; and six-year old group was composed of $47 \%$ ) girls and 53\% boys. All children included in the sample were typically developed children.

\subsection{Data Collection Instrument - Basic School Skills Inventory-3}

Basic School Skills Inventory-3 was developed by a group of researchers as a result of long observations and research between 1971-1998 (Hammill, Leigh, Pearson, \& Maddox, 1998). It is prepared to be used by the teachers of the children of 4-8 age group to acquire the right knowledge regarding the basic skill, which is required for a successful school performance. In the construction of BSSI-3, two main elements are considered. The first is the teacher of the class; he/she should play a primary role in assessing children's performance professionally, with the most comprehensive and practical knowledge of children's day-to-day functioning and study. The second one is that the scale can make an assessment to reflect on the skills and competencies that are directly related to various duties and activities which are carried out by the children aged 4-8 in school for them to be ready for school performance. It consists of 137 items and six sub-tests. These subtests are; Spoken Language, Reading, Writing, Mathematics, Classroom Behaviour and Daily Living skills. Each sub-dimension has about 20 and 26 items.

In this research, a validity-reliability study was conducted to determine whether three sub-tests were appropriate for Turkish children aged 4-6 years in the population of the study to be used in BSSI-3 primary school readiness studies. These subtests are; Mathematics, Daily living skills and Classroom behaviour. Assessment of BSSI-3 with a 4-point Likert scale is as follows; 0-Does not perform, 1-Beginning to perform, 2-Perform most of the time 3-performance indicates mastery. There is no inverse scoring on the BSSI-3 scoring. Teachers score 0-3 for the items on the scales. The high scores obtained from the sub-test scores indicate that the children have developed and have a high proportion of those skills. BSSI-3 includes teachers' evaluation of children by considering their experiences with the children. To calculate the child's score, the child's calendar age is found when she/he takes the test and the individual results of each child are assessed through the total score obtained or the \% (percentage) that corresponds in the score table for 4-8 ages that is attached. 
In his research, Lyman (1998) mentioned the five permanent sources of error in the test applications. 1-the content of the test, 2-the duration of the application, 3-the control score, 4-the situation (noise, no breaks, insufficient light etc. affecting the performance of practitioner) 5 - testes.

Regarding BSSI-3; 1- The content along with the test validity and reliability have been tested in BSSI-3. More than ten provinces of America have been tested for validity and reliability. The reliability factor of all inventory is calculated as 90 (Hammill, Leigh, Pearson, Maddox, 1998). 2-There is no limit to the duration of the application. Evaluation should be stopped when the child or the teacher loses focus. In this study, 10-15 minutes are recommended for three subtest applications for each child. 3- An individual assessment table is available for each group of children aged 4-8 on the back of the BSSI-3 reference book. 4-Teachers are warned about environments that negatively affect the performance of the practitioner. 5- The test is evaluated by the teachers of the children aged 4-6. The test is not a diagnostic test and should be evaluated by the teacher. According to researchers, teachers' countless experience and observation during the day provide more persistent and accurate reviews in grading scale (Likert-type grading scale) (Gresham, 1986). Moreover, the Teachers know the children in their classrooms and are the useful and reliable reports of skill levels of the students (Gerber, Semmel, 1984). In collecting data for this study, the kindergarten teachers with more than five years of professional experience have been preferred for application of three sub-tests of BSSI-3 inventory that is provided for teacher applications. In this study, mathematics, daily life skills and classroom behaviour subtests of the Basic School Skills Inventory-3 were tested for validity and reliability for Turkish children.

The BSSI-3 contains three subtests, which are described below:

Description of Mathematics; The 20 items in this subtest measure knowledge of numerical concepts and arithmetic operations involved in beginning mathematics. Mathematical evaluations; numbers consist of recognition, saying, choosing, writing, quantity, relation, equivalence and simple arithmetic calculations. Each item represents a skill that is essential for successful math performance in the elementary.. With regard to the implementation and evaluation of BSSI-3, each sub-item is given a description for each item. For example: 17. item of subtest mathematic: "Uses a calculator to add and subtract". Rationale: The calculator increasingly has become an important instrument in mathematics instruction over the years. Even young children can learn how to use this techonology to assist in performing mathematical computations. Mastery: Give the child a standard pocket calculator. Show one addition problem and one subtraction problem to the child. Both problems should involve computation of to single-digit numbers. The child must use the calculator correctly to compute the answers to both problems in order to receive full credit.

Daily living skills; The 24 items in this subtest measure the basic knowledge and skills typically required for participating in day-to-day activities in school. Areas assessed include primary self-care behaviours, motor behaviours directly related to school activities and behaviours needed to function independently. Items pertain to basic information that young children must acquire during the early years. Items reflect a child's background of experience, including prior parental instruction and influence. Children do well on these items are likely to be those who are considered independent and responsible in school. Regarding the skills of daily living as 12. item: Tells own birth date (e.g.,April 4; June 6) Rationale: Bird days are generally important events in children's lives. They should be able to racite their bird date when asked. Mastery: The child must say the name of the month and day in which he or she was born to receive full credit.

Description of Classroom Behaviour; The 23 items included in this subtest represent behaviours that teacher have indicated are of common concern, even though the degree of behavioural variance that can be tolerated within the classroom cannot be standardized from one teacher to another. The items assess specific behaviours that provide information pertaining to a child's attentiveness, cooperating, attitude, socialization, and work habits. Behavioural assessment is particularly important given that lack of academic success can often be attributed to behavioural rather than cognitive or linguistic deficiencies. We can give the example of the 18th item about classroom behavior. Interprets and responds to everyday social situations appropriately. Rationale: Throughout the school day, children interact in social contexts. Some children frequently misunderstand or overreact to the comments or actions of others. Mastery: Full credit is given to the child who consistently accurately perceives and appropriately responds to the intentions and behaviors of other people (Hammill, Leigh, Pearson \& Maddox, 1998).

\subsubsection{Turkish Adaptation of Basic School Skills Inventory-3}

For the Turkish Adaptation of Basic School Skills Inventory, the researcher and a language expert initially translated into Turkish the English form. It was then translated by an expert back into English using "backward translation" and compared to the original items. A degree of agreement was observed between Turkish and original English items. Later, nine experts working in the area of child development and education were requested to evaluate whether the test and items were suitable for children aged four-six and also for Turkish culture. Based on the expert views, it was accepted 
that Basic School Skills Inventory was clear to understand, adequate and suitable for Turkish culture and content validity.

\subsection{Analysis of the Data}

Validity and reliability analyses of Basic School Skills Inventory-3 were performed using the data obtained from 595 children. Validity of the test was assessed through content validity, construct validity and concurrent validity. Reliability of the test was ensured using internal consistency, split-half test and test-retest reliability methods. Research data was analyzed with SPSS 20.0 (Statistical Package for Social Sciences). Cronbach's Alpha formula was used to measure internal consistency reliability.

\section{Results}

\subsection{Validity of Basic School Skills Inventory-3 (Mathematic, Daily Life and Classroom Behavior)}

Validity refers to how well a test measures what it is purposed to measure. Different classifications are available for validity techniques. Of these, the most popular ones were used in the present study; content validity, construct validity and concurrent validity (Büyüköztürk, 2012).

\subsubsection{Content Validity of Basic School Skills Inventory}

Content validity refers to the qualitative and quantitative adequacy of test items to measure the traits and characteristics to be measured (Büyüköztürk, 2012). In other words, it is the ability for research findings to be generalized to larger samples being explored.

During the content validity of the research, 9 experts from the field of child development and education have been asked whether BSII-MAT, BSII-DLS and BSII-CB fully cover the developmental characteristics of the 4-6-year old Turkish children. Each question has, "appropriate", "correctable" or "inapropriate" sections. At first observation, according to experts, no questions were omitted from the 20 questions of mathematics sub-test, one question was omitted from 24 questions of daily life skills test and arranged with 23 questions. One question was omitted from 22 questions of classroom Behaviors sub-test and arranged with 22 questions. The data were collected from Konya and its vicinity.

Interclass correlation was calculated to be .89 for Basic School Skills Inventory-3 Mathematic, .92 for Daily Life and .88 for Classroom Behavior. It is accepted that the Basic School Ability Inventory has content validity based on the expert reviews.

\subsubsection{Construct Validity of Basic School Skills Inventory-3}

Construct validity refers to whether or how well a test measures the constructs that it is designed to measure. Exploratory factor analysis was performed for the construct validity of Basic School Skills Inventory. Kaiser-Meyer-Olkin coefficient (KMO) and Bartlett's test of Sphericity were performed with the intent of determining whether the data fit the factor analysis or not. KMO coefficient tests whether the sample size fits and is adequate for the factor analysis. The data provides good fit for the factor analysis when the KMO coefficient is as near 1 as possible (Büyüköztürk, 2012).

In this study, KMO coefficient was found to be .948 for Mathematic test, .920 for Daily Life test and .970 for Classroom Behavior test. In social sciences, a KMO coefficient higher than .60 indicates the fitness and adequacy of sample size for factor analysis. Bartlett's test of Sphericity tests whether the data comes from multivariate normal distribution and whether the variables are correlated or not. The data is said to come from multivariate normal distribution and is correlated when the Chi-Square value obtained following this test is significant (Büyüköztürk, 2012). In the study, Bartlett's test of Sphericity performed for Mathematic Test $\left(X^{2}=993,186 ; p<.001\right)$, for Daily Life test $\left(X^{2}=654,186 ; p<.001\right)$ and for Classroom Behavior test $\left(X^{2}=112,71 ; p<.001\right)$ were found significant; the results indicated fitness of the data for factor analysis.

Principal Components Factor Analysis reduced the factors or underlying structures known as components included in Basic School Skills Inventory-Mathematic Test, Daily Life Test and Classroom Behavior Test. The analysis revealed two factors with an eigenvalue higher than 1 . The scree plot showing the change in eigenvalue was examined in order to determine the number of important factors. It was seen in the graphic that there were minor differences in the direction of the line following factor 1 and they made approximate contributions to the variance. Thus, the number of factors in the Mathematic test, Daily life test and Classroom Behavior test were determined as one according to the eigenvalue criterion. Exploratory Factor Analysis results of the tests are presented in Table 1. 
Table 1. Exploratory Factor Analysis results for Basic School Skills Inventory-3 Mathematic Test, Daily Life Test and Classroom Behavior Test

\begin{tabular}{|c|c|c|c|c|c|c|c|c|c|c|c|c|}
\hline \multirow{5}{*}{ Mathematic Test } & $I 1$ & $I 2$ & 13 & I4 & I5 & I6 & $I 7$ & I8 & 19 & $I 10$ & & Variance \\
\hline & .77 & .82 & .81 & .80 & .78 & .74 & .85 & .80 & .79 & .63 & & Explained $=\% 56.23$ \\
\hline & $I 11$ & $I 12$ & $I 13$ & $I 14$ & $I 15$ & $I 16$ & $I 17$ & $I 18$ & $I 19$ & $I 20$ & & $\mathrm{KMO}=.948$ \\
\hline & .24 & .71 & .67 & .32 & .70 & .55 & .64 & .79 & .82 & .80 & & \multirow{2}{*}{$\begin{array}{l}\text { Barlett's } \quad \text { Test } \\
\text { Sphericity=993.186 } \\
\text { p<.001 }\end{array}$} \\
\hline & & & & & & & & & & & & \\
\hline \multirow{5}{*}{ Daily Life Test } & II & $I 2$ & $I 3$ & I4 & $I 5$ & I6 & $I 7$ & $I 8$ & 19 & $I 10$ & I11 I12 & Variance \\
\hline & .56 & .70 & .71 & .62 & .76 & .39 & .52 & .65 & .76 & .72 & $.37 \quad .26$ & Explained $=\% 37$ \\
\hline & $I 13$ & $I 14$ & $I 15$ & $I 16$ & $I 17$ & $I 18$ & $I 19$ & $I 20$ & $I 21$ & $I 22$ & $I 23$ & \\
\hline & .48 & .56 & .67 & .47 & .56 & .70 & .53 & .61 & .64 & .70 & .69 & \multirow{2}{*}{$\begin{array}{l}\text { Barlett's } \quad \text { Test } \\
\text { Sphericity }=654.186 \\
p<.001\end{array}$} \\
\hline & & & & & & & & & & & & \\
\hline \multirow{5}{*}{$\begin{array}{l}\text { Classroom } \\
\text { Behavior Test }\end{array}$} & $I 1$ & $I 2$ & $I 3$ & $I 4$ & 15 & I6 & $I 7$ & 18 & 19 & $I 10$ & I11 & Variance \\
\hline & .64 & .73 & .73 & .72 & .71 & .74 & .73 & .54 & .69 & .65 & .64 & $\begin{array}{l}\text { Total Varrance } \\
\text { Explained }=\% 60.33\end{array}$ \\
\hline & $I 12$ & $I 13$ & $I 14$ & $I 15$ & $I 16$ & $I 17$ & $I 18$ & $I 19$ & $I 20$ & $I 21$ & $I 22$ & $\mathrm{KMO}=.970$ \\
\hline & .73 & .76 & .72 & .77 & .78 & .77 & .70 & .69 & .69 & .69 & .63 & $\begin{array}{lr}\text { Barlett's } \quad \text { Test } \\
\text { Sphericity=112.71 }\end{array}$ \\
\hline & & & & & & & & & & & & $\mathrm{p}<.001$ \\
\hline
\end{tabular}

Table 1 show that the items including the Mathematic, Daily Life and Classroom Behavior Tests of Basic School Skills Inventory-3 were grouped under a single factor. The proportions of the variance explained by these single factors were $\% 56.23$ (for Mathematic Test), \%37 (for Daily Life Test) and \%60.33 (for Classroom Behavior Test). Given the common threshold of 30 percent, the results indicated that the test had a single factor (Cokluk, Sekercioglu \& Buyukozturk, 2010). Principal components analysis showed factor loadings of Mathematic Test items ranged from .24 to .85, Daily Life Test items ranged from .26 to .76 and Classroom Behavior Test items ranged from .54 to .78 . According to Büyüköztürk, Börekoğlu and Köklü (2008), items with factor loading of .30 or higher can discriminate an individual from another; items between .20 and .30 need to be excluded or corrected if necessary and items with a factor loading of .20 or lower should not be included in the test. Therefore, no item was excluded from the tests and the Mathematic Test was composed of 20 items and one factor, the Daily Life Test was composed of 23 items and one factor, the Classroom Behavior Test was composed of 22 items and one factor.

\subsubsection{Concurrent Validity of Basic School Skills Inventory-3}

Concurrent validity refers to the correlation between the scores participants achieved in two different tests serving the same purpose (Büyüköztürk, 2012). For its concurrent validity, Basic School Skills Inventory-3 Mathematic Test was compared to the Observed Early Number Test (Menevşe, 2016; Van Luit \& Van de Rijt, 2009) to see whether there was a correlation or not. 17 children were included in the concurrent validity study for Mathematic Test. Tests were administered to the children by the researcher himself (a period of two days between tests) in a quiet environment with tables and chair using materials essential to collect data. Table 2 summarizes the results of Mathematic Test concurrent validity.

Table 2. Correlation between Basic School Skills Inventory Mathematic Test and Observed Early Number Test

\begin{tabular}{|c|c|c|c|}
\hline & & $\begin{array}{l}\text { Basic School Skills Inventory } \\
\text { Mathematic Test }\end{array}$ & Observed Early Number Test \\
\hline \multirow{3}{*}{$\begin{array}{l}\text { Basic School Skills Inventory } \\
\text { Mathematic Test }\end{array}$} & Pearson Correlation & 1 & $.609 * *$ \\
\hline & Sig. (2-tiled) & & .009 \\
\hline & $\mathrm{n}$ & & 17 \\
\hline \multirow[t]{3}{*}{ Observed Early Number Test } & Pearson Correlation & $.609 * *$ & 1 \\
\hline & Sig. (2-tiled) & .009 & \\
\hline & $\mathrm{n}$ & 17 & \\
\hline
\end{tabular}

***Correlation significant at level .050.

Table 2 shows a positive and significant relationship between children's scores from Basic School Skills Inventory Mathematic Test and the Observed Early Number Test; $r=0.609, \mathrm{p}<.050$. Correlation coefficient of 0.60 to 1.00 
indicates a strong correlation (Büyüköztürk, 2012). In this sense, a strong correlation existed between children's scores on two tests administered to them. Consequently, as the scores children achieved in Basic School Skills Inventory Mathematic Test increase, so do their scores on the Observed Early Number Test.

Basic School Skills Inventory Daily Life Test was compared to the 33-66 Months Children's Self-Care Skills Assessment Scale (Bayer, 2015) to see whether there was correlation or not. 20 children were included in the concurrent validity study for Daily Life Test. Tests were administered to the children by the researcher himself (a period of two days between tests) in a quiet environment with tables and chair using materials essential to collect data. Table 3 summarizes the results for Daily Life Test concurrent validity.

Table 3. Correlation between Basic School Skills Inventory Daily Life Test and 33-66 Months Children's Self-Care Skills Assessment Scale

\begin{tabular}{|c|c|c|c|}
\hline & Basic $\quad$ School Skills Inventory & 33-66 Months Children's \\
\hline & & Daily Life Test & Self-Care Skills Assessment Scale \\
\hline Basic School Skills Inventory & Pearson Correlation & 1 & $.556 * *$ \\
\hline Daily Life Test & Sig. (2-tiled) & & .011 \\
\hline & $\mathrm{n}$ & & 20 \\
\hline Children's & Pearson Correlation & $.556^{* *}$ & 1 \\
\hline Self-Care Skills Assessment & Sig. (2-tiled) & .011 & \\
\hline Scale & $\mathrm{n}$ & 20 & \\
\hline
\end{tabular}

**Correlation significant at level .050 .

Table 3 shows a positive and significant relationship between children's scores from Basic School Skills Inventory Daily Life Test and the 33-66 Months Children's Self-Care Skills Assessment Scale; $r=0.556, p<.050$. In this sense, a moderate correlation existed between children's scores on two tests administered to them. Consequently, as the scores children achieved in Basic School Skills Inventory Daily Life Test increase, so do their scores on the 33-66 Months Children's Self-Care Skills Assessment Scale.

\subsection{Reliability of Basic School Skills Inventory-3 (Mathematic, Daily Life and Classroom Behavior)}

Reliability refers to the consistency of the responses given to the items of an assessment tool and shows the stability of measure. Reliability is how well an instrument measures what it is supposed to measure (Büyüköztürk, 2012). In order to determine the reliability of Basic School Skills Inventory (Mathematic, Daily life and Classroom Behavior), internal consistency coefficients, split-half reliability and test- retest reliability analyses were performed.

\subsubsection{Internal Consistency of Basic School Skills Inventory-3}

The internal consistency of Basic School Skills Inventory-3 was assessed in age-groups with Cronbach Alpha formula. Cronbach Alpha reliability coefficients are presented in Table 4.

Table 4. Cronbach Alpha Reliability Coefficients for Age Groups

\begin{tabular}{llll}
\hline Basic School Skills Inventory & Age Group & $\mathrm{n}$ & Cronbach Alpha \\
\hline \multirow{3}{*}{ Mathematic Test } & 4 years old & 99 & .97 \\
& 5 years old & 244 & .94 \\
& 6 years old & 252 & .87 \\
Daily Life Test & 4 years old & 99 & .90 \\
& 5 years old & 244 & .91 \\
& 6 years old & 252 & .88 \\
Classroom Behavior Test & 4 years old & 99 & .97 \\
& 5 years old & 244 & .93 \\
\hline
\end{tabular}

As seen in Table 4, the reliability coefficient of Basic School Skills Inventory-3 Mathematic Test is .97 ( $\mathrm{n}=99$ ) for four year-old children, $.94(\mathrm{n}=244)$ for five year-old children and $.87(\mathrm{n}=252)$ for six year-olds. The reliability coefficient of Basic School Skills Inventory-3 Daily Life Test is .90 $(n=99)$ for four year-old children, .91 $(n=244)$ for five year-old children and $.88(\mathrm{n}=252)$ for six year-olds. The reliability coefficient of Basic School Skills Inventory-3 Classroom Behavior Test is $.97(\mathrm{n}=99)$ for four year-old children, $.93(\mathrm{n}=244)$ for five year-old children and $.93(\mathrm{n}=252)$ for six year-olds. For a psychological test, a reliability coefficient of .70 and higher is considered satisfactory for the reliability of test scores (Büyüköztürk, 2012). Accordingly, Cronbach Alpha reliability coefficients calculated separately for each group provided evidence for the reliability of Basic School Skills Inventory.

\subsubsection{Split-Half Test Reliability of Basic School Skills Inventory}

For the split-half test reliability, all items of a test are split in halves as odd and even numbers, first and second half or 
two random halves and the correlation between two halves is determined using Spearman Brown formula (Büyüköztürk, 2012). In the present study, the test was divided into two halves as first and second half and the correlation between these two halves was calculated. Reliability coefficients calculated for each groups are presented in Table 5.

Table 5. Split-Half Reliability of Basic School Skills Inventory

\begin{tabular}{llll}
\hline Basic School Skills Inventory & Age Group & $\mathrm{n}$ & Spearman Brown \\
\hline \multirow{3}{*}{ Mathematic Test } & 4 years old & 99 & .96 \\
& 5 years old & 244 & .96 \\
& 6 years old & 252 & .89 \\
\hline \multirow{3}{*}{ Daily Life Test } & 4 years old & 99 & .86 \\
& 5 years old & 244 & .88 \\
Classroom Behavior Test & 6 years old & 252 & .84 \\
& 4 years old & 99 & .87 \\
& 5 years old & 244 & .91 \\
\hline
\end{tabular}

Table 5 shows the split-half reliability coefficients of Basic School Skills Inventory for the age groups. The reliability coefficient calculated for Basic School Skills Inventory Mathematic Test is .96 $(\mathrm{n}=99)$ for four year-old children, .96 $(\mathrm{n}=244)$ for five year-old children and $.89(\mathrm{n}=252)$ for six year-olds. The reliability coefficient calculated for Basic School Skills Inventory Daily Life Test is $.86(\mathrm{n}=99)$ for four year-old children, $.88(\mathrm{n}=244)$ for five year-old children and $.84(\mathrm{n}=252)$ for six year-olds. The reliability coefficient calculated for Basic School Skills Inventory Classroom Behavior Test is .87 $(\mathrm{n}=99)$ for four year-old children, .91 $(\mathrm{n}=244)$ for five year-old children and $.91(\mathrm{n}=252)$ for six year-olds. These values show that split-half reliability coefficient of the tests is adequate.

\subsubsection{Test-Retest Reliability of Basic School Skills Inventory}

Test-Retest Reliability shows the correlation between measures obtained by administering the same test twice over a period of time to the same group. Usually, a period of four weeks between two measures is considered ideal (Büyüköztürk, 2012). For that reason, Basic School Skills Inventory was administered to 28 children for the second time four weeks later and the consistency of children's responses to each item was analyzed. Test- Retest reliability calculated by Wilcoxon Signed Rank Test and the values are presented in Table 6.

Table 6. Test- Retest Reliability of Basic School Skills Inventory

\begin{tabular}{lllllll}
\hline Basic School Skills Inventory & $\mathrm{n}$ & Mean Rank & Sum of Ranks & $\mathrm{z}$ & $\mathrm{p}$ \\
\hline \multirow{3}{*}{ Mathematic } & Negative Ranks & 11 & 11.95 & 131.50 & $-.529^{\mathrm{a}}$ & .59 \\
Test & Pozitive Ranks & 13 & 12.96 & 168.50 & & \\
& Equal & 4 & & & & \\
\hline \multirow{3}{*}{ Daily Life Test } & Notal & 28 & & & & \\
& Pozative Ranks & 10 & 13.05 & 130.50 & $-1.146^{\mathrm{a}}$ & .252 \\
& Equal & 2 & & 220.50 & & \\
& Total & 28 & & & & \\
\hline \multirow{3}{*}{$\begin{array}{l}\text { Classroom } \\
\text { Behavior Test }\end{array}$} & Negative Ranks & 6 & 8.25 & 49.50 & $-.189^{\mathrm{a}}$ & .850 \\
& Pozitive Ranks & 8 & 6.94 & 55.50 & & \\
& Equal & 14 & & & & \\
& Total & 28 & & & & \\
\hline
\end{tabular}

${ }^{a}$ Based on negative ranks

As Table 6 shows, there is no statistically significant difference between test and retest scores of Mathematic Test $(\mathrm{z}=-.529, \mathrm{p}>.05)$, Daily Life Test $(\mathrm{z}=-1.146, \mathrm{p}>.05)$ and Classroom Behavior Test $(\mathrm{z}=-.189, \mathrm{p}>.05)$. The data obtained suggests that test-retest reliability of Basic School Skills Inventory is satisfactory.

\section{Conclusion}

This study presents the Turkish adaptation and reliability and validity analysis of Basic School Skills Inventory (Mathematic, Daily Life and Classroom Behavior) developed by Hammill, Leigh, Pearson \& Maddox (1998). Validity of the test was determined through content validity, construct validity and concurrent validity. Expert views were taken to check the content validity and all the experts agreed that the test serves its purpose of measuring children's basic school skills (mathematic, daily life and classroom behavior). Construct validity of the Basic School Skills Inventory was established through a factor analysis approach. Kaiser-Meyer-Olkin coefficient (KMO) and Bartlett's test of Sphericity were performed with the intent of determining whether the data fits the factor analysis or not and it was 
concluded that the research sample was convenient and representative in mathematics, daily life and classroom behavior tests of Basic School Skills Inventory. Bartlett's test of Sphericity was found significant in mathematics, daily life and classroom behavior tests, which indicated that the data was suitable enough to use for factor analysis. Based on Principal Components Analysis, factor analysis was made to explore the factor structure of the test and 20 items in the mathematic test were grouped together on a single factor, 23 items in the daily life test were grouped together on a single factor and 22 items in the classroom Behavior test were grouped together on a single factor. A positive and significant relationship was found between children's scores on Basic School Skills Inventory Mathematic test and Observed Early Number Test. As children's scores on Basic School Skills Inventory Mathematic Test increase, so do their scores on the Observed Early Number Test. In addition, a positive and significant relationship was found between children's scores on Basic School Skills Inventory Daily Life Test and 33-66 Months Children's Self-Care Skills Assessment Scale. As children's scores on Basic School Skills Inventory Daily Life Test increase, so do their scores on the 33-66 Months Children's Self-Care Skills Assessment Scale. Reliability of Basic School Skills Inventory was established through Internal-consistency reliability, split-half reliability and test-retest reliability. Internal consistency reliability was calculated using Cronbach Alpha formula and higher Cronbach Alpha reliability coefficients calculated for each age group provide evidence for the reliability of the test. In the split-half reliability, the test was administered as two separate tests (first half and second half) and the correlation coefficient between two halves was calculated using Spearman Brown formula. Calculations showed that split-half reliability coefficient of the test was adequate. Following the first measure, the test was administered to 28 children for the second time four weeks later. There was no statistically significant difference between test and retest scores of Mathematic Test, Daily Life Test and Classroom Behavior Test. The data obtained suggests that test-retest reliability of Basic School Skills Inventory is satisfactory.

Overall, the research results indicated that Basic School Skills Inventory (Mathematic, Daily Life and Classroom Behavior Tests) is a valid and reliable instrument to measure four to six year old Turkish children's basic school skills.

\section{References}

Atkinson, R. L., Atkinson, R. C., Smith, E. E., Bem, D. J., \& Hoeksema, S. N. (1999). Introduction Psychology (12th Edition). (S. Erkonaç, D. \& Y. Alogan, Çev.) Ankara: Arkadaş Press.

Bayer, A. (2015). Examination of the effect of Montessori Method on preschool children (36-66 mounth) self care skills. Unpublished Master Thesis. Selcuk University, Institude of Social Sciences, Konya.

Büyüköztürk, Ş. (2012). Data Analysis Handbook for Social Sciences (2nd Edition) Ankara: Pegem Akademik Press.

Büyüköztürk, Ş., Börekoğlu, Ö., \& Köklü, N. (2008). Statistics for Social Sciences (2nd Edition) Ankara: Pegem Akademik Press.

Duncan, G. J., Dowsett, C. J., Claessens, A., Magnuson, K., Huston, A. C., Klebanov, P., \& Sexton, H. (2007). School readiness and later achievement. Developmental Psychology, 43(6), 1428-1446. https://doi.org/10.1037/0012-1649.43.6.1428

Ekşi, A. (1999). I'm not ill. Ankara: Nobel Medical Bookstore.

Gander, M. J., \& Gardiner, H. W. (2007). Child and Adolescent Development (6th Edition). (B. Onur., Dönmez, N. H. Çelen, \& B. Onur, Trans.) İstanbul: İmge Bookstore.

Hammill, D. D., Leigh, J. E., Pearson, N. A., \& Maddox, T. (1998). Basic School Skills Inventory A Readiness Measure for Teacher. Austin-Texsas: Pro-ed an International Publisher.

Karoly, L. A., Kilburn, M. R., \& Cannon, J. S. (2005). Early Childhood Interventions: Proven Results, Future Promise. Santa Monica, CA: RAND.

Menevşe, E. B. (2016). The validity and reliability study of the early postnatal test for children aged 48-84 months. Unpublished Master Thesis. Necmettin Erbakan University, Institute of Educational Sciences, Konya.

Montessori, M. (1978). The Montessori Method. (S. J. Mann, \& N. İnan, D.) Ankara: Association for the Protection of Children with Mental Retardation.

Montessori, M. (2015). Absorbent Mind. Istanbul: Kaknüs Publications.

Montessori, M. (2016). What you need to know about your child. (S. D. Çiftçi, \& Z. Baykul, Trans.) İstanbul: Kaknüs Publications.

Newcomb, A. F., Bukowski, W. M., \& Pattee, L. (1993). Children's peer relations: A meta-analytical review of popular, rejected, neglected, controversial, and average sociometric status. Psychological Bulletin, 113, 99-128. https://doi.org/10.1037/0033-2909.113.1.99

Öztürk, O. (1994). Mental Health and Disorders. Ankara: Physicians Publishing Association. 
Trawick-Smith, J. (2013). Early Child Development. Ankara: Nobel Akademik Press.

Van Luit, J. E. H., \& Van De Rijt, B. A. M. (2009). Deutrechtse number consept test-revised; The importance of early signaling. Journal of Orthopedagogics - Tijdschrift Voor Orthopedagogiek, 48, 255-270.

Yıldız, F. Ü., \& Kayılı, G. (2015). Examination of the effects of computer assisted preschool educational activities on children's intuitive mathematical ability. Journal of Advances in Humanities and Social Sciences, 1(1), 1-8.

\section{Copyrights}

Copyright for this article is retained by the author(s), with first publication rights granted to the journal.

This is an open-access article distributed under the terms and conditions of the Creative Commons Attribution license which permits unrestricted use, distribution, and reproduction in any medium, provided the original work is properly cited. 